\title{
Estimation of arterial oxygen tension in adult subjects using a transcutaneous electrode
}

\author{
D C S HUTCHISON, G ROCCA, AND D HONEYBOURNE
}

From the Chest Unit, King's College Hospital, London

\begin{abstract}
Transcutaneous oxygen tension $\left(\mathrm{tcPO}_{2}\right)$ measured with a heated electrode was compared with arterial oxygen tension $\left(\mathrm{PaO}_{2}\right)$ in three groups of adult patients-group A: 20 patients with chronic respiratory disease; group B: eight hypothermic patents studied immediately after cardiopulmonary bypass surgery; and group $\mathrm{C}: 14$ patients in an intensive care unit who had in all 35 comparisons of $\mathrm{tcPO}_{2}$ and $\mathrm{PaO}_{2}$. For group $\mathrm{A}$, the relationship of the two methods is given by the regression equation (in $\mathrm{mmHg}$ ): $t \mathrm{tcO}_{2}=0.88 \mathrm{PaO}_{2}+5.0$ (standard error $=$ $5.2: \mathrm{r}=0.93: \mathrm{p}<0.001$ ) and for group $\mathrm{C} \mathrm{tcPO}_{2}=0.69 \mathrm{PaO}_{2}+14.9$ (standard error $=12.0, \mathrm{r}=0.90$ : $\mathrm{p}<0.001$ ). A method of in vivo calibration using a single arterial blood sample improved the reliability of the method in group $\mathrm{C}$. In the group B patients there was no correlation between tcPO ${ }_{2}$ and $\mathrm{PaO}_{2}$ even when supplementary heating was applied to the skin. Continuous monitoring can reveal large fluctuations in arterial $\mathrm{PO}_{2}$ which would be missed by the use of intermittent arterial samples. The transcutaneous electrode can be employed usefully in intensive care monitoring of adult patients and in physiological studies where repeated arterial samples would otherwise be required.
\end{abstract}

The transcutaneous oxygen electrode ${ }^{12}$ is a Clark polarographic electrode adapted for application to the skin surface. The electrode used in this study incorporates at the anode a small thermostatically controlled heater, designed to produce hyperaemia of the underlying skin and thus arterialisation of the local capillary circulation. It was shown in adult subjects that the oxygen tension measured by the transcutaneous method $\left(\mathrm{tcPO}_{2}\right)$ correlated with the directly measured arterial oxygen tension $\left(\mathrm{PaO}_{2}\right)^{1}$ and similar comparative studies have been carried out in healthy and sick newborn infants. ${ }^{3-6}$ Rapid alterations in $\mathrm{tcPO}_{2}$ have been observed during aspiration and other manoeuvres associated with mechanical ventilation and there is no doubt that continuous monitoring by this method can reveal fluctuations which could not be observed by intermittent arterial sampling.

The validation of the transcutaneous electrode as a reliable non-invasive method of monitoring arterial $\mathrm{PO}_{2}$ is a matter of general interest and to date the bulk of this work has been carried out in

Address for reprint requests: Dr DCS Hutchison, Chest Unit, King's College Hospital, Denmark Hill, London SE5 8RX. newborn infants. In the present study we have set out to determine the accuracy of the method in adult patients and to examine its possible role in physiological investigation or in the management of patients undergoing intensive care.

\section{Methods}

The transcutaneous oxygen electrode (Drägerwerk, Lübeck, West Germany) has three platinum microcathodes (diameter $15 \mu \mathrm{m}$ ) surrounded by a heated anode, and covered by a $25 \mu \mathrm{m}$ Teflon membrane enclosing a thin layer of electrolyte solution. The design is similar to that described by Huch et al. ${ }^{1}$ The anode was heated to $45^{\circ} \mathrm{C}$ in these studies. The electrode was calibrated in vitro at two points before each study. The lower calibration point (zero oxygen tension) was obtained by placing a drop of sodium sulphite solution on the Teflon membrane. For the upper calibration point (atmospheric air) the electrode was placed in a plastic container of approximately $50 \mathrm{ml}$ and surrounded by gauze soaked in warm water. The pressure of aqueous vapour at the anode temperature of $45^{\circ} \mathrm{C}$ is $72 \mathrm{mmHg}$ and this figure was subtracted from 
the barometric pressure. The system used is similar to that described by Pollitzer et $a l^{6}$ who found that full saturation with aqueous vapour was not achieved by this method; they added a correction factor of $4 \mathrm{mmHg}$ to the observed partial pressure of oxygen in atmospheric air. A similar discrepancy was found in this study and the same factor was added.

For measurement of $\mathrm{tcPO}_{2}$, a drop of distilled water was placed on the skin and the electrode attached with an adhesive ring. Care was taken to ensure a watertight seal and to exclude air bubbles. The skin over the biceps was chosen in most cases. The flexor aspect of the forearm was used in some of the cases studied immediately after cardiopulmonary bypass surgery (group B).

The output of the transcutaneous electrode could be read digitally or displayed on a chart recorder.

When the output of the electrode had reached a steady value, an arterial blood sample was obtained for estimation of oxygen tension either by brachial or radial artery puncture or from an arterial cannula where this had previously been inserted for the purposes of intensive care monitoring. Arterial puncture produced no fluctuations in the transcutaneous oxygen record. Samples were analysed within five minutes using a Corning blood-gas analyser (type 165) which was calibrated with nitrogen and air before each estimation. The blood-gas readings were multiplied by 0.95 , the ratio of blood to gas readings at a given oxygen tension, as established by tonometry.

Three groups of patients were studied. Group A included 20 stable ambulant outpatients or inpatients with chronic respiratory disease. Arterial blood samples were obtained by brachial or radial puncture in the course of routine investigation. Group B contained eight hypothermic patients within two hours of cardiopulmonary bypass surgery. An arterial cannula was in situ in all. Six patients were studied again subsequently and are included in group C. Local skin temperature adjacent to the transcutaneous electrode was monitored with a thermistor probe. In four patients, a coil of plastic tubing fed by warm water from a thermostatcontrolled heater and circulating pump was placed around the arm and insulated so that the electrode was completely enclosed. Local skin temnerature was raised to between $37^{\circ} \mathrm{C}$ and $40^{\circ} \mathrm{C}$ by this method. Group $\mathrm{C}$ included nine patients who had undergone cardiopulmonary bypass surgery 24 or more hours previously (six of these had been previously studied-see group B) and five patients who were suffering primarily

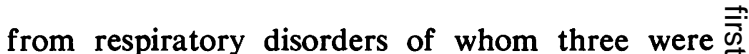
receiving assisted ventilation. None was hypo- $\bar{C}$ thermic and cardiovascular status was satisfactory. $\frac{\bar{\sigma}}{\bar{*}}$ All had an arterial cannula in situ and were in the $\frac{\bar{N}}{7}$ intensive care unit.

In 10 of the group $C$ cases it was possible to vary the inspired oxygen concentration so that a number of comparisons of $\mathrm{tcPO}_{2}$ and $\mathrm{PaO}_{2}$ could be made in the same individual. A method of in vivo $\vec{\omega}$ calibration of the transcutaneous electrode could $\odot$ thus be carried out using the relationship between $\overrightarrow{\vec{x}}$ the initial pair of $\mathrm{tcPO}_{2}$ and $\mathrm{PaO}_{2}$ results to correct $\omega_{\sigma}$ the subsequent $\mathrm{tcPO}_{2}$ observations as follows: $\mathrm{o}$ corrected $\mathrm{tcPO}_{2}=$ observed $\mathrm{tcPO}_{2} \times$ initial $\left(\mathrm{PaO}_{2} /\right.$ i $\mathrm{tcPO}_{2}$ ).

\section{Results}

ELECTRODE PERFORMANCE

A stable output was normally obtained $15-20 \mathrm{~min}-\vec{\varphi}$ utes after application to the subject but in the $\stackrel{\infty}{\rightarrow}$ group B patients stability of ten took much longer 0 to achieve. Calibration drift at the upper point was 2 to $4 \mathrm{mmHg}(0 \cdot 3-0.5 \mathrm{kPa})$ over two hours. There was no drift in the zero reading.

After stabilisation, a step-change in the inspired $\frac{2}{\otimes}$ $\mathrm{O}_{2}$ concentration led to the establishment of a new plateau within six minutes in normal subjects and within 10 minutes in the patients of groups $A$ and $C$. There was a lag of about 30 seconds after the step-change before a response was seen. The electrode was not left in situ for more than one hour. A mild erythema was seen at the electrode site in most subjects.

\section{GROUP B PATIENTS}

In the eight patients studied immediately after cardiopulmonary bypass surgery, there was no cor- 은 relation between $\mathrm{tcPO}_{2}$ and $\mathrm{PaO}_{2} \cdot \mathrm{PaO}_{2}$ ranged $\rightarrow$ from 82 to $218 \mathrm{mmHg}(10.9-29.1 \mathrm{kPa})$ but the 을 highest $\mathrm{tcPO}_{2}$ recorded was only $105 \mathrm{mmHg}(14.0 \mathrm{~N}$ $\mathrm{kPa}$ ). In general, the electrode recordings took longer to equilibrate than in groups $A$ and $C, N$ in two cases as long as $\mathbf{4 0}$ minutes.

The skin temperature adjacent to the electrode ranged from $28.4^{\circ} \mathrm{C}$ to $32^{\circ} \mathrm{C}$. The heating coil was 6

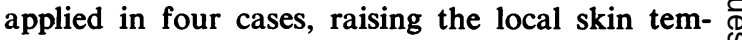
perature by $6^{\circ}$ to $12^{\circ} \mathrm{C}$ over a period of $40 \mathrm{~min}-\stackrel{\oplus}{?}$ utes. No significant increase in the observed $\mathrm{tCPO}_{2}$ was achieved by this method.

\section{GROUP A PATIENTS}

In the 20 patients with chronic respiratory disease, $\mathrm{PaO}_{2}$ ranged from 50 to $104 \mathrm{mmHg}(6.7-13.9 \mathrm{kPa})$; the last figure was obtained in a patient breathing 
$28 \% \mathrm{O}_{2}$. The regression of $\mathrm{tcPO}_{2}$ on $\mathrm{PaO}_{2}$ in $\mathrm{mmHg}$ is given by the following equation:

$$
\mathrm{tcPO}_{2}=0.88 \mathrm{PaO}_{2}+5.0
$$

Standard error of estimate $=5 \cdot 2$

$(\mathrm{r}=0.93: \mathrm{p}<0.001)$

\section{GROUP C PATIENTS}

Fourteen patients were studied and by alteration of the inspired oxygen concentration, 35 comparisons of $\mathrm{tcPO}_{2}$ and $\mathrm{PaO}_{2}$ were available. $\mathrm{PaO}_{2}$ ranged from 44 to $184 \mathrm{mmHg}(5.9-24.5 \mathrm{kPa})$. For the standard in vitro method of calibration, the regression of $\mathrm{tcPO}_{2}$ on $\mathrm{PaO}_{2}$ in $\mathrm{mmHg}$ is given by:

$$
\begin{aligned}
& \mathrm{tcPO}_{2}=0.69 \mathrm{PaO}_{2}+14.9 \\
& \text { Standard error of estimate }=12.0 \\
& (\mathrm{r}=0.90: \mathrm{p}<0.001)
\end{aligned}
$$

When groups $\mathrm{A}$ and $\mathrm{C}$ were pooled (fig 1), the combined regression equation of $\mathrm{tcPO}_{2}$ on $\mathrm{PaO}_{2}$ showed no significant departure from a straight line relationship. The equation (in $\mathrm{mmHg}$ ) is:

$$
\begin{aligned}
& \text { tcPO } \\
& \text { Standard error of estimate }=0.69 \mathrm{PaO}_{2}+16.1 \\
& (r=0.92: \mathrm{p}<0.001)
\end{aligned}
$$

IN VIVO CALIBRATION (fig 2)

Ten of the group $C$ patients had more than one
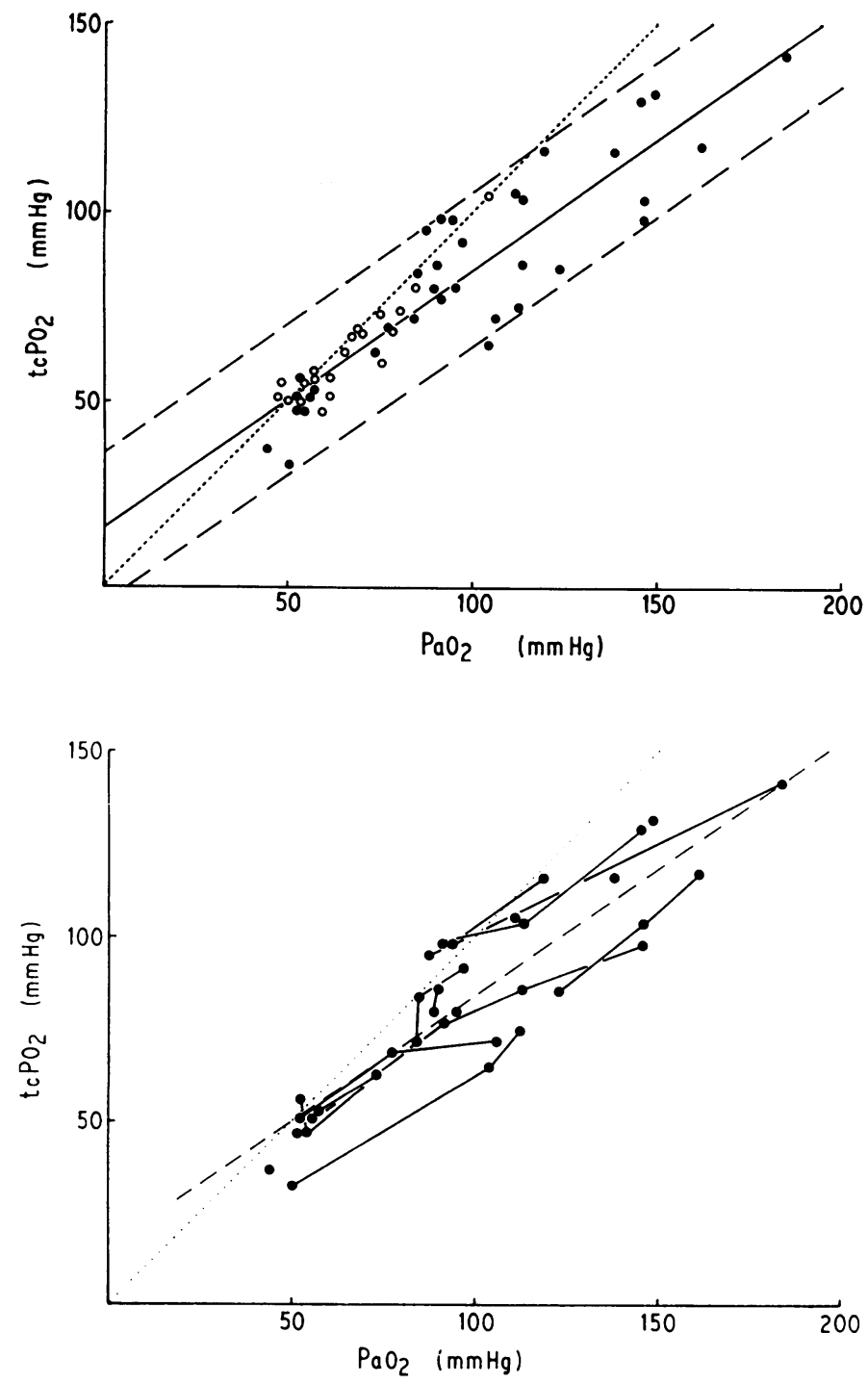

Fig 1 Relationship between $t \mathrm{CPO}_{2}$ and $\mathrm{PaO}_{2}$ in 34 patients. Group $\mathrm{A}(\mathrm{O})$ contained 20 patients with chronic respiratory disease (one pair of estimations for each patient). Group C $(\bullet)$ included 14 patients in intensive care units (35 paired estimations in toto). Combined regression equation for groups $A$ and $C(\mathrm{mmHg}): t c \mathrm{PO}_{2}=0.69 \mathrm{PaO}_{2}+16 \cdot 1$. $=$ regression line, $---=95 \%$ confidence limits, $\cdots=$ line of identity. Conversion to SI units: $1 \mathrm{kPa}=$ $0.133 \mathrm{~mm} \mathrm{Hg}$.

Fig 2 Relationship between $t c \mathrm{PO}_{2}$ and $\mathrm{PaO}_{2}$ in 20 paired observations from 10 patients of group $C$ who had more than one comparison-in vivo calibration. Regression equation: $t \mathrm{POO}_{2}=0.69 \mathrm{PaO}_{2}+$ $30 \cdot 1(r=0.87: p<0.001)--\longrightarrow=$ regression line, $\cdots=$ line of identity. Points derived from individual patients are linked-the initial pair of observations from which the correction factor is derived is omitted. 
(two to five) estimations in the same session. Twenty comparisons of corrected $\mathrm{tcPO}_{2}$ and $\mathrm{PaO}_{2}$ were available by the in vivo calibration method. The regression equation in $\mathrm{mmHg}$ is as follows:

Corrected $\mathrm{tcPO}_{2}=0.69 \mathrm{PaO}_{2}+30.1$

$(\mathrm{r}=0.87: \mathrm{p}<0.001)$

The mean $\mathrm{PaO}_{2}$ for the 20 estimations was $98.2 \mathrm{mmHg}(13.1 \mathrm{kPa})$. The mean $\mathrm{tcPO}_{2}$ (in vitro calibration) was $82.3 \mathrm{mmHg}(11.0 \mathrm{kPa})$ and mean $\mathrm{tcPO}_{2}$ (in vivo calibration) $97.5 \mathrm{mmHg}(13.0 \mathrm{kPa})$.

\section{Discussion}

In the patients with chronic respiratory disease (group A), we have shown that measurement of $\mathrm{tcPO}_{2}$ can give a reasonable estimate of $\mathrm{PaO}_{2}$ in the range 50 to $100 \mathrm{mmHg}(6.7-13.3 \mathrm{kPa})$, with standard error $5.2 \mathrm{mmHg}(0.7 \mathrm{kPa})$. For the group $\mathrm{C}$ patients who were undergoing treatment in an intensive care unit (but not in the immediate postoperative period) the agreement between $\mathrm{PaO}_{2}$ and $\mathrm{tCPO}_{2}$ was less good, with a standard error of $12 \cdot 0$. The slope of the regression equation was less steep in the group $\mathrm{C}$ patients, suggesting a tendency to under-read the $\mathrm{PaO}_{2}$ at higher values with the in vitro calibration method in use. On statistical testing, however, there was no departure from a linear relationship.

The discrepancies between $\mathrm{tcPO}_{2}$ and $\mathrm{PaO}_{2}$ arise for a number of reasons. The $\mathrm{Po}_{2}$ recorded at the transcutaneous electrode will tend to be lower than the true arterial $\mathrm{Po}_{2}$ because of oxygen consumption by the skin itself. On the other hand, the temperature of the skin immediately underlying the heated electrode is several degrees above that of normal arterial blood. It has been shown that such elevation of temperature displaces the oxyhaemoglobin dissociation curve to the right producing an increase in $\mathrm{PO}_{2}$ at a given haemoglobin saturation. ${ }^{7}$ The final $\mathrm{tcPO}_{2}$ thus reflects a balance between these two factors.

The discrepancies between $\mathrm{tCPO}_{2}$ and $\mathrm{PaO}_{2}$ are also likely to be related to variations in the methods used to calibrate the transcutaneous and arterial blood electrodes. The in vitro method of calibrating the transcutaneous electrode using nitrogen and saturated atmospheric air as in this study, is appropriate to the conventional blood-gas analyser, but bears little similarity to the operating mode of the transcutaneous electrode. Use of the subject's own arterial blood would thus seem to be the only certain way of obtaining the upper calibration point: zero oxygen tension can however be chosen as the lower calibration point and here nitrogen or a reducing solution is satisfactory.
This in vivo method of calibration could only bes? used by us in the group C patients; a closer estio mate of $\mathrm{PaO}_{2}$ was achieved, though the correlationo coefficient was not improved.

It could be argued that the necessity of ob- $\frac{\mathbb{D}}{\Omega}$ taining an arterial blood sample to perform thes initial in vivo calibration negates the non-invasiveprinciple exemplified by the transcutaneous elec-ㅇ trode. However, a single arterial puncture care $-\vec{\omega}$ fully performed is a virtually painless procedure with a very low complication rate; once this has been done, the virtues of the transcutaneous elec- $\omega$ trode as a non-traumatic continuous monitoringos device can be used. After the initial estimation of $A$ $\mathrm{PaO}_{2}$, the transcutaneous electrode system couldw be set to this value and subsequent estimates? viewed with greater confidence.

In the patients who were studied immediately气 after cardiopulmonary bypass surgery (group B), no correlation between $\mathrm{tcPO}_{2}$ and $\mathrm{PaO}_{2}$ was found. $\overrightarrow{0}$ The intense vasoconstriction associated with $a \stackrel{\infty}{-}$ major operation under hypothermia evidently prevents diffusion of oxygen from the arterialo blood to the skin surface and this could not be overcome even when a heating coil was applied, raising the local skin temperature to a value be- $\frac{\mathrm{D}}{\mathrm{O}}$ tween $37^{\circ} \mathrm{C}$ and $40^{\circ} \mathrm{C}$. The transcutaneous electrode would therefore be of little value in moni-o toring $\mathrm{PaO}_{2}$ in such patients. In practice, however, an arterial cannula would have been inserted, so the necessity for transcutaneous oxygen measurements would seldom arise; a poor correlation between $\mathrm{tCPO}_{2}$ and $\mathrm{PaO}_{2}$ in very hypotensive infants@ has already been observed. ${ }^{5}$

Further experience is undoubtedly required to 3 establish the validity and general usefulness of transcutaneous oxygen measurements in the adult $₹$ patient. Some improvement in the absolute ac-o curacy of the method could no doubt be achieved but it is clear that any changes in $\mathrm{tcPO}_{2}$ could be을 regarded with much greater confidence. It seems likely that the method would be of value in the in-o tensive care unit where the continuous record $N$ would have a considerable advantage over the more usual method of intermittent arterial sampl-O ing. Neonatal experience has shown unexpectedlyo wide fluctuations in $\mathrm{tCPO}_{2}$ and early warning of such changes allows intervention at an earlier stage? than would otherwise be possible. Similar findings are obtained when the method is applied to the adult subject. In addition, a reasonable estimate of $\mathrm{PaO}_{2}$ can be obtained in patients from whomฉ arterial samples cannot be obtained such as aত thrombocytopenic patient studied by us. Again, $\Omega$ by virtue of its rapid response and non-invasiveo 
character, the method has a useful role in more purely physiological investigations such as muscular exercise where it may be impractical or unethical to obtain arterial blood samples.

We are indebted to Draeger Medical Ltd for the loan of the electrode system, to the anaesthetists, physicians, and surgeons in charge of patients in the Intensive Care Unit, to the technical staff of the Chest Unit, to Dr E Moyle who devised the heating coil, and to Dr D Bellamy. We also thank the staff of the Neonatal Intensive Care Unit and of the Department of Medical Physics, University College Hospital and Medical School and Professor EOR Reynolds for their help.

\section{References}

1 Huch A, Huch R, Arner B, Rooth G. Continuous transcutaneous oxygen tension measured with a heated electrode. Scand J Clin Lab Invest 1973; 31:269-75.
2 Eberhard P, Hammacher K, Mindt W. Methode zur kutanen Messung des Sauerstoff partialdruckes. Biomed Tech 1973; 6:216-21.

3 Huch R, Lübbers DW, Huch A. Reliability of transcutaneous monitoring of arterial $\mathrm{Po}_{2}$ in newborn infants. Arch Dis Child 1974; 49:213-8.

4 le Souëf PN, Morgan AK, Soutter LP, Reynolds EOR, Parker D. Comparison of transcutaneous oxygen tension with arterial oxygen tension in newborn infants with severe respiratory illnesses. Pediatrics 1978; 62:692-7.

5 Peabody JL, Gregory GA, Willis MW, Tooley WH. Transcutaneous oxygen tension in sick infants. Am Rev Respir Dis 1978; 118:83-7.

6 Pollitzer MJ, Whitehead MD, Reynolds EOR, Delpy D. Effect of electrode temperature and in vivo calibration on accuracy of transcutaneous estimation of arterial oxygen tension in infants. Pediatrics 1980; 65:515-22.

7 Bradley AF, Stupfel M, Severinghaus JW. Effect of temperature on $\mathrm{PCO}_{2}$ and $\mathrm{Po}_{2}$ of blood in vitro. J Appl Physiol 1956; 9:201-4. 